\title{
THE IMPLEMENTATION OF FUZZY SETS IN DECISION MAKING PROCESS
}

\author{
Snežana Konjikušić ${ }^{1 *}$, \\ Gordana Radojević \\ Ana Vjetrov ${ }^{1}$ \\ ${ }^{1} \mathrm{FEFA}$, \\ Belgrade, Serbia \\ 2Direktna banka, \\ Belgrade, Serbia
}

\begin{abstract}
:
The focus of this paper is the system for supporting financial decision-making as well as the possibility of its upgrading in order to get close to the conditions that apply and exist within real business environment. In this paper, the problems of defining the relevant criteria will be considered, as well as the presentation and implementation of an adequate model for evaluating the company that appears as the loan applicant. Within the paper, the model for financial decision support is defined, based on fuzzy logic and applicable within banking sector. Therefore, the aim of this paper is to improve financial decision-making process in the banks by applying the concepts and models related to decision support systems, with the strong focus on decision-making support systems based on knowledge and intelligent decision support systems.
\end{abstract}

Keywords:

fuzzy model, decision problems, finances.

\section{INTRODUCTION}

Making financial decisions represents one of the most common problems in current financial management. One of the most important things within process of making financial decision is related to credit decisions. Both importance and complexity of this issue represent the main logic why so many efforts in the previous years have been made in order to formulate the methods that would tackle this problem most realistically. The need for applying suitable and efficient methods and procedures is confirmed, bearing in mind that the underlying problem is very complex and therefore difficult to apply to the confining hypotheses on which mathematical models are often build. Various models based on decision support systems are frequently used for solving similar problems.

Today, financial decision support is very interesting topic for various surveys, both in theoretical and practical sense. In modern banking, financial decision-making based on financial analysis plays very important role. Intensive research in the past, regarding the issue of financial decision-making, has led to the introduction of various methods that are used as systems to support the process of making financial decisions (Dalalah et.al, 2011). These systems are based on various mathematical methods and they are being effectively implemented in everyday banking practice.

The issue related to making financial decision was first clarified by classical methods of multi-criteria decision-making. This approach has the advantage in

Correspondence: Snežana Konjikušić

e-mail: skonjikusic@fefa.edu.rs the sense that it is clearly mathematically described, but its disadvantage is the fact that connection with the real life activities is missing.

Further changes regarding classical model were made in various directions (Altrock, 1996). 
All these changes were made with the same goal and it was to bring the models closer to the real life situation with respect to the real conditions and limitations. Criteria for making a financial decision can be expressed quantitatively and qualitatively, taking into account the subjectivity of the decision-maker i.e. - the criteria sometimes involve subjective attitudes or personal preferences (Brotons \& Terceno, 2011). Thus, these values are sometimes characterized by inaccuracy and uncertainty. The common limitation of classical models relates to the fact that sometimes criterion values are understood rigidly, i.e. two alternatives (credit requirements) will be acknowledged the same by some criterion only if the values of that criterion are identical, and if there is slight variation in value, one alternative will be seen more suitable, which does not coincide with reality where preferences are not always that rigid (Zimmerman, 2001). All this has led to a slight change related to the ways of observing the modelling of the problem of making financial decision.

By applying the fuzzy logic related to decision support systems, intelligent decision support systems are gained, representing a step forward in decision theory (Klir \& Folger, 1998). The models obtained in this way can be successfully implemented in the process of financial decisionmaking, since they are more consistent with the real life activities. By designing and implementing such a realistic model, a powerful tool is gained whose role is to help the decision maker to achieve his goal that relates to making a valid financial decision.

\section{FUZZY EXPERT SYSTEM}

The analysis related to model of making financial decision, where financial analysis is used, emphasizes an area that can be advanced by suggesting fuzzy concepts, which involves qualitative assessment procedures. The value of qualitative indicators represents linguistic expressions and they can be presented by fuzzy sets. The main rationale for implementing the fuzzy concepts is the fact that they are appropriate for presenting linguistic values and translating them into real, quantitative values.

By introducing membership functions for each parameter, showing the cognitive state of things, a more flexible and realistic knowledge representation system is obtained (Hadavandi et.al, 2010). The fuzzy approach enables the manipulation of expert knowledge at a high level of abstraction in the form of linguistic variables. This feature is very important for the success of the functioning of entire expert system and represents a novelty in comparison to classical expert systems. Expert knowledge in the fuzzy expert system is presented in the form of rules expressed by linguistic variables, which is very real and close to the man-expert and his way of reasoning.
The fuzzy concept enables expert knowledge to be presented in a computer system at a high level of abstraction; in the shape of if/then rules with linguistic indicators in the way the expert himself recognizes them (Yu et.al, 2009).

\section{FUZZY DECISSION- MAKING MODEL}

The developed fuzzy model related to making financial decision is used for the qualitative evaluation of the company. The fuzzy model related to making financial decision was implemented using the MatLab software package (Sivanandam, at.al, 2007). Within MatLab software, fuzzy toolbox was used in order to solve decision-making problems. Fuzzy model related to financial decision-making process includes: defining the key parameters related to the model (number of output and input variables, defining the basic logical operations); defining a set of attributes for every input and output variable; defining a set of rules for calculating the value of an output variable; interpretation of the obtained results.

Table 1 shows the qualitative indicators of the company (input variables of the model) and the qualitative score (output variable) as well as the associated attributes, and the value of input variables which is determined by the decision - maker who assigns a rating from the interval $[0,1]$ to each of the qualitative indicators (Barjaktarović et.al, 2017). A set of attributes is defined for all qualitative linguistic variables. A larger or smaller number of attributes can be used, but in this paper three attributes are used as the optimal number for an efficient presentation of this model. Every attribute is described by a single fuzzy set. In this paper, trapezoidal shapes are used for fuzzy sets i.e. attributes (Radojević \& Konjikušić, 2004). The presented variables will be the basis for the fuzzy model used for determining of the qualitative score of the company. 
Table 1. Input variables, attributes and weight factors:

\begin{tabular}{|c|c|c|}
\hline \multicolumn{3}{|c|}{ Input variables, attributes and weight factors: } \\
\hline Variables & Attributes & Weight factors \\
\hline Competition analysis & $\begin{array}{l}\text { Uncompetitive } \\
\text { Equally competitive } \\
\text { More competitive }\end{array}$ & 0.2 \\
\hline $\begin{array}{l}\text { Company's reliance on the } \\
\text { customer }\end{array}$ & $\begin{array}{l}\text { High } \\
\text { Average } \\
\text { Weak }\end{array}$ & 0.1 \\
\hline $\begin{array}{l}\text { Company's reliance on the } \\
\text { supplier }\end{array}$ & $\begin{array}{l}\text { High } \\
\text { Average } \\
\text { Weak }\end{array}$ & 0.1 \\
\hline Market size & $\begin{array}{l}\text { Decreasing } \\
\text { Stable } \\
\text { Increasing }\end{array}$ & 0.3 \\
\hline Accounting quality & $\begin{array}{l}\text { Poor quality } \\
\text { Average } \\
\text { Good }\end{array}$ & 0.1 \\
\hline Continuity of doing business & $\begin{array}{l}\text { Not provided } \\
\text { Provided }\end{array}$ & 0.2 \\
\hline \multicolumn{3}{|c|}{ Output variable } \\
\hline Qualitative score & $\begin{array}{l}\text { Dissatisfactory } \\
\text { Relatively satisfactory } \\
\text { Satisfactory }\end{array}$ & \\
\hline
\end{tabular}

Source: Authors' calculation

Within the process related to the fuzzy model implementation, the following components are defined: input and output indicators (variables), logical operations that will be applied within the process of making financial-decision and the method of defuzzification. Figure 1 shows the screen from MatLab, where specified model parameters are being defined.

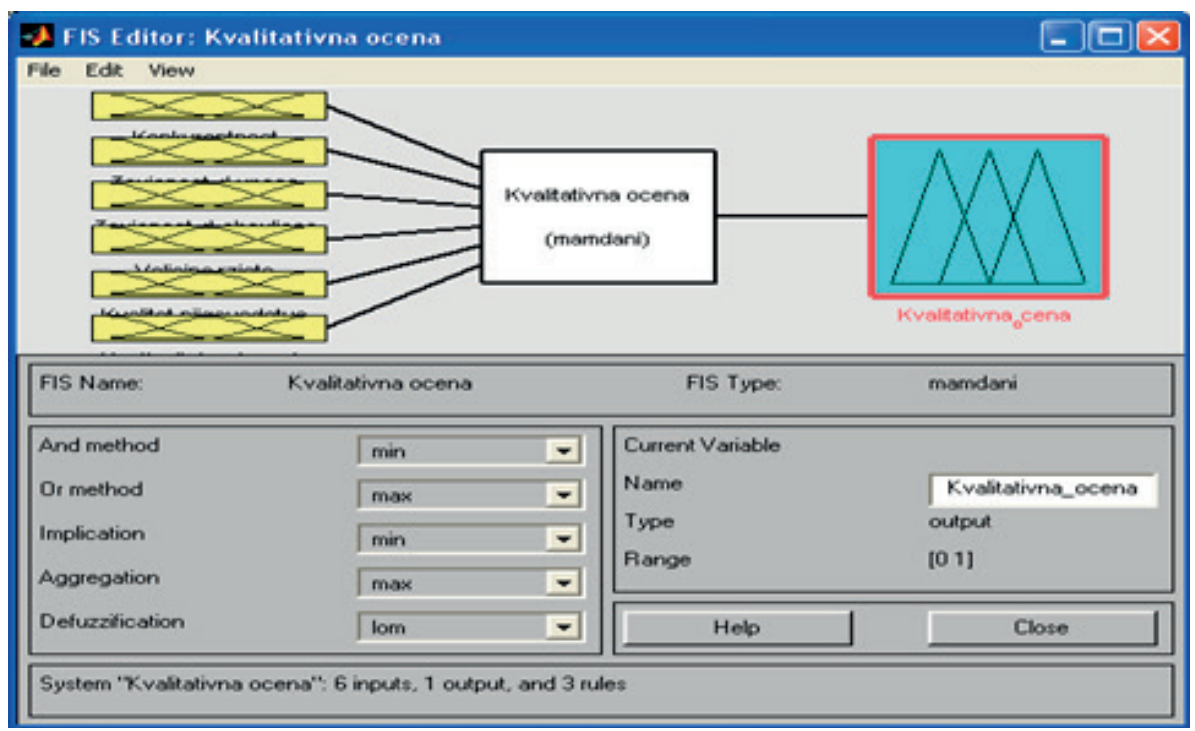

Figure 1. Basic model parameters

Figure 2 represents a screen from MatLab showing the definition of one of the six input variables, and other model variables are defined in a similar way. Figure 3 presents the definition of output variable. 


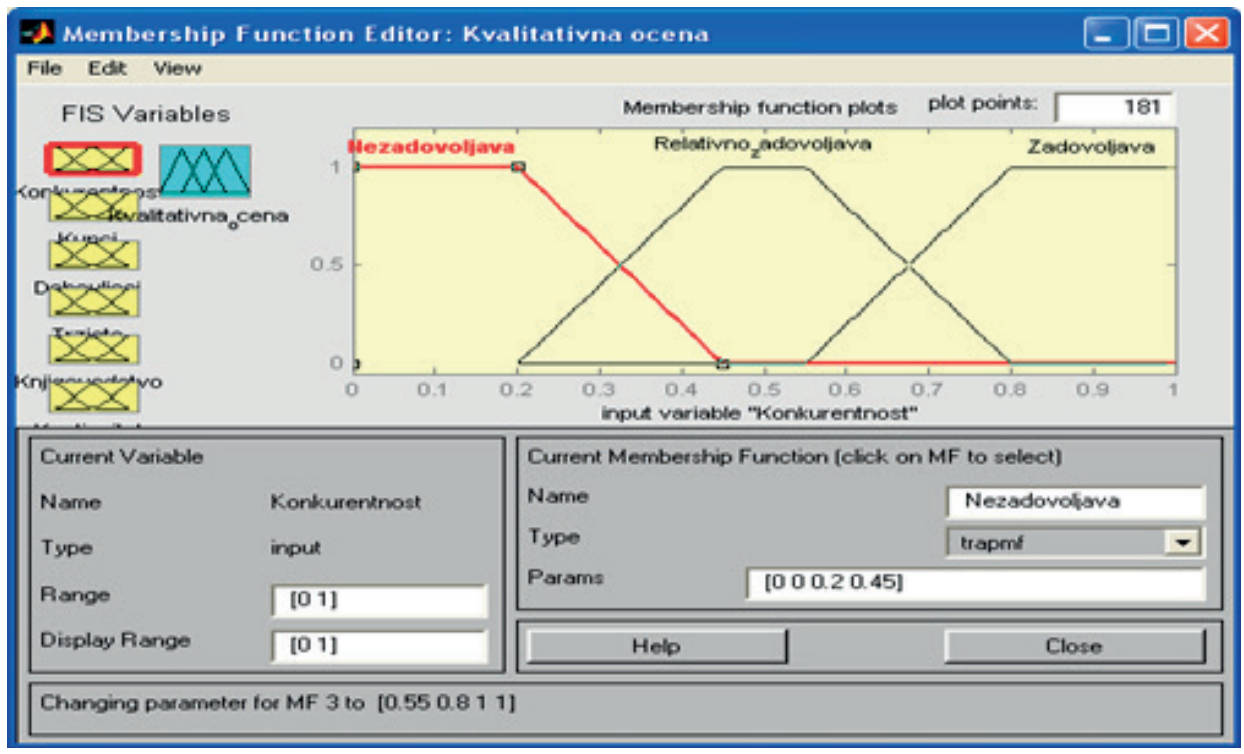

Figure 2. Definition of input variable Competitiveness assessment

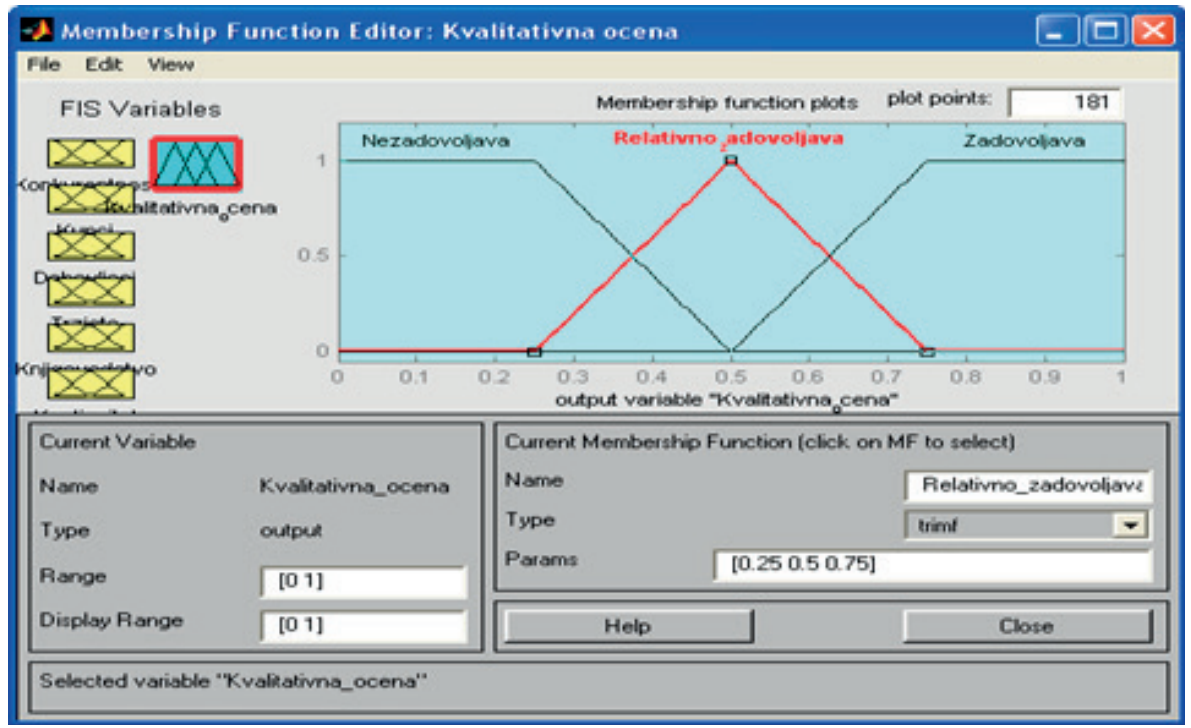

Figure 3. Definition of output variable

The following reasoning rules are defined for calculating the qualitative score of the company:

- When the value related to all input variables is Unsatisfactory then the value related to the output variable is Unsatisfactory

- When the value of at least one of the input indicators (variables) is different from Unsatisfactory then the value related to the output variable is Relatively satisfactory

- When the value related to all input indicators (variables) is Satisfying, then the value related to the output variable is Satisfying.
These rules can be defined in a different way, depending on the both needs and preferences related to the decisionmaker. Finally, Figure 4 shows the rule viewer screen related to the values of the input indicators (variables) presented in Table 1 . The qualitative score is 0.34 . 


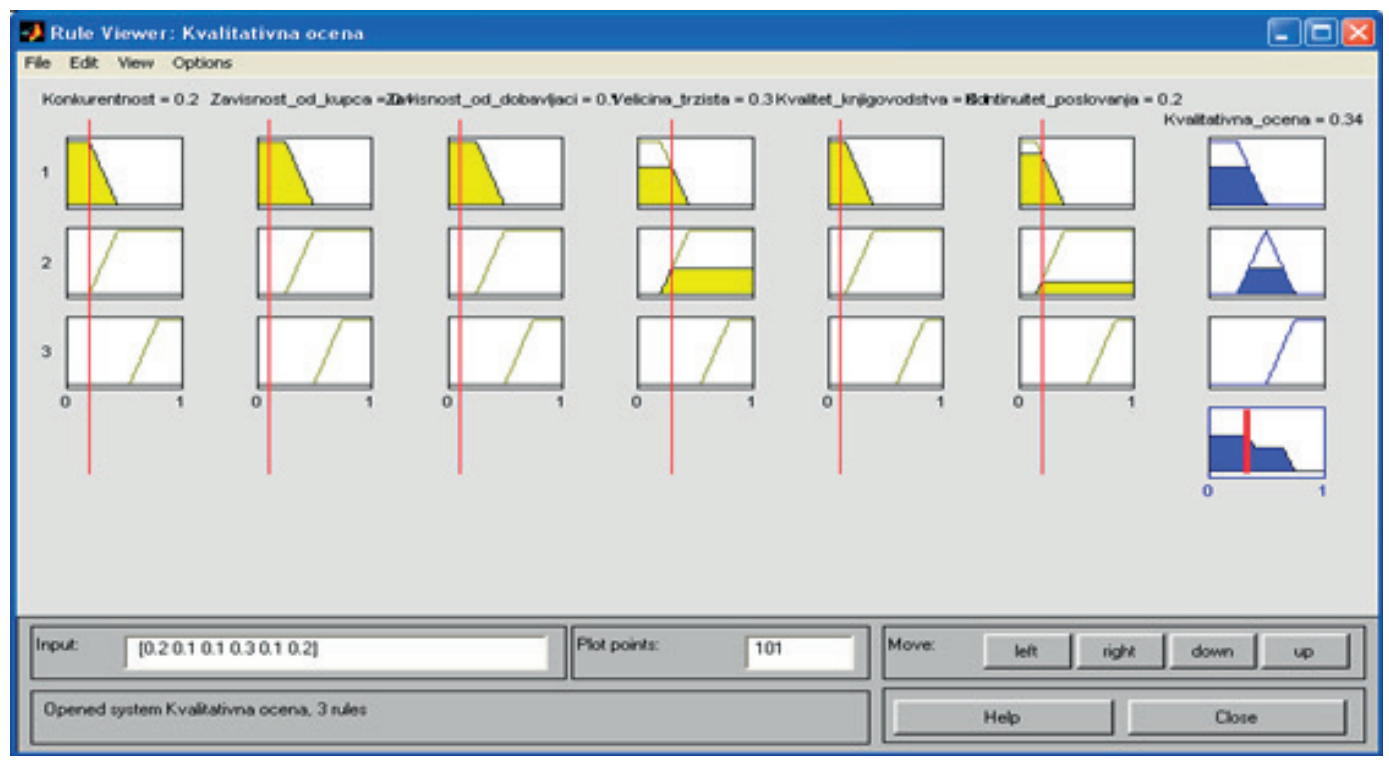

Figure 4 . The qualitative score for the values $(0.2,0.1,0.1,0.3,0.1,0.2)$

Within the process of making decision, as an output outcome, the output fuzzy variable was obtained, which is described by a set of related attributes, i.e. linguistic variables. Every attribute is described by a single fuzzy set (Cross \& Sudkamp, 2002). The defined fuzzy model related to decision-making as an output gives the fuzzy set and defuzzified score, i.e. the model also gives us the value related to the output variable in a discrete form, i.e. number. In this model, defuzzification was done by using the lom method (largest of maximum)

The Rule viewer shows a score as a fuzzy set and a defuzzified score. By analyzing the values of qualitative indicators shown in Table 1, it can be said that the qualitative score of the company is satisfactory, reaching the level of 0.34 . It should be considered that the obtained score has range from 0 to 1 . As the final decision related to the accepting of the obtained score can be made by comparing the obtained results with a predefined reference value, for instance, the score can be considered acceptable when it is higher than 0.8 if a more rigorous approach is being implemented, or if it is higher than 0.3 if there is a more flexible approach being implemented. The qualitative score obtained within this process does not represent the final score of the company's performance, upon which credit decision should be made (Yalçın et.al, 2009). The qualitative analysis represents one of several partial evaluations of the company's performance that will jointly form the final score of the company's performance, upon which the lending decision will be made.

\section{CONCLUSION}

Support systems related to decision making, as well as decision support systems that are knowledge-based and intelligent decision support systems, represent a very important field of scientific research that has found its application within a large number of areas of human activity. Further, these systems are intensively being implemented in financial decision-making process. This paper systematizes the lessons learnt acquired during the research in the field of application of these systems within financial decision- making process.

An important element of financial decision-making is the process of financial analysis with all its components financial indicators, their calculation and interpretation in order to determine the financial position and performance of the company. The main focus of this paper is the evaluation of the chosen company and making lending decision. Balance sheet analysis is a key but not the only component covered by the valuation process of a given company. A very important component is also the analysis of other, non-financial parameters that are expressed qualitatively, i.e. descriptive.

The paper presents a fuzzy model as the instrument for financial decision support, i.e. making a lending decision related to the chosen company by introducing a fuzzy concept. Fuzzy logic is an important tool for modelling activities defined by uncertainty, inaccuracy and information asymmetry (Konjikušić \& Radojevć, 2008). This was the main reason why fuzzy sets were used in this paper as the instrument for modelling the values of the chosen parameters which were used for the company's valuation. In this way, indicator values, both financial and non-financial, are no longer defined by numbers but they are 
defined by fuzzy sets. In this way, the modelled variables are joined together in order to obtain the overall score related to the company' performance, by implementing the fuzzy model rules of conclusion. Thus, the model that is presented in the paper is an example of fuzzy expert system, together with all its important features and components: knowledge base (rules of financial analysis, rules of company performance evaluation), reasoning mechanism, modules for fuzzification and defuzzification.

Within this paper, the role of an intelligent system for financial decision support based on the fuzzy logic is presented. The model was implemented, which is simultaneously using both theoretical aspects within the field of uncertainty and inaccuracy, and practical experience within the field of financial analysis and financial decision-making. In this way, a decision support system that is applicable within the banking sector was obtained.

\section{ACKNOWLEDGMENT}

We would like to thank dr Lidija Barjaktarovic from the Singidunum University for her support regarding valuable suggestions for improving the quality of the research.

\section{LITERATURE}

1Altrock, C.V. (1996). Fuzzy and Neuro Fuzzy in Business and Finance. Prentice Hall.

Barjaktarović, L., Đulić, K., Pinđžo, R. \& Vjetrov, A. (2017). Analiza primene ERM koncepta u Srbiji: Uporedna analiza finansijskog i realnog sektora. Bankarstvo, 2017, vol. 46, br. 2 50, 50-68.

Brotons, J. \& Terceno, A. (2011). Return Risk Map in a Fuzzy Environment. Fuzzy Economic Review 16, No. 2.

Cross, V. \& Sudkamp, T. (2002). Similarity and Compatibility in Fuzzy Set Theory: Assessment and Applications. Springer Science \& Business Media.

Dalalah, D., Hayajneh, M. \& Batieha, F. (2011). A fuzzy multicriteria decision making model for supplier selection. Expert Systems with Applications, Volume 38, Issue 7, 8384-8391.

Hadavandi, E., Shavandi, E. \& Ghanbari, A. (2010). Integration of genetic fuzzy systems and artificial neural networks for stock price forecasting. Knowledge-Based Systems, Volume 23, Issue 8, 800-808.

Klir, G. J. \& Folger, T. A. (1998). Fuzzy Sets, Uncertainty and Information. Prentice Hall.

Konjikušić, S. \& Radojevć G. (2008). Višekriterijumsko odlučivanje u uslovima neizvesnosti. XIII međunarodni simpozijum SYMORG 2008, Beograd.

Radojević, G. \& Konjikušić, S. (2004). Višekriterijumski modeli izbora investicija upotrebom fuzzy skupova, SymOrg 2004, Zlatibor.
Sivanandam, S. N., Sumathi, S. \& Deepa, S.N. (2007). Introduction to Fuzzy Logic using MATLAB. Springer, 277-320.

Yalçın, N., Bayrakdaroglu, A. \& Kahraman, C. (2009). Fuzzy performance evaluation in Turkish Banking Sector using Analytic Hierarchy Process and TOPSIS. Expert Systems with Applications, Volume 36, Issue 9, 11699-11709.

Yu, L., Wang, S. \& Lai, K.K. (2009). An Intelligent-AgentBased Fuzzy Group Decision-Making Model for Financial Multicriteria Decision Support: The Case of Credit Scoring. European Journal of Operational Research 195, No. 3: 942-959.

Zimmerman, H. (2001). Fuzzy Set Theory - and Its Applications. Springer Science \& Business Media. 